\title{
Akromegali hastalarında benign ve malign tümör sıklığı
}

\author{
Malign and benign tumor frequency in patients with acromegaly
}

Nusret Yılmaz, Gökhan Tazegül, Ramazan Sarı, Hasan Ali Altunbaş, Mustafa Kemal Balcı

Gönderilme tarihi: 07.12.2019

Kabul tarihi: 29.04 .2020

Özet

Amaç: Bu çalışmada tek bir merkezde izlenen akromegali hastalarındaki benign ve malign tümör sıklığının belirlenmesi amaçlanmıştır.

Gereç ve yöntem: Toplam 92 akromegali hastasının kayıtları retrospektif olarak incelendi. Hastaların temel klinik karakteristikleri ile hastalarda mevcut olan benign ve malign tümörlerin özellikleri ve sıklıkları değerlendirildi.

Bulgular: Hastaların medyan yaşları 51 (26-83) yıl, 52'si (\%56,5) kadın ve 40'ı $(\% 43,5)$ erkek idi. Hastaların $\% 4,3$ 'ünde $(n=4)$ malignite mevcuttu. Saptanan malignitelerin tümü tiroid papiller karsinomu idi. Hastaların $\% 76,1$ 'inde en az bir benign tümör vardı. Tiroid ultrasonografisi (USG) yapılan hastaların ( $n=74) \% 76$ 'sında $(n=57)$ tiroid nodülü, kolonoskopi yapılan hastaların $(n=70) \% 21,4$ 'ünde $(n=15)$ kolon polipi, abdominal USG yapılan hastaların $(n=72) \% 5,5$ 'inde $(n=4)$ safra kesesi polipi, meme görüntülemesi yapılan kadınların $(n=52)$ $\% 11,5$ 'inde $(n=6)$ benign meme lezyonu mevcuttu.

Sonuç: Sonuç olarak akromegali hastalarında artmış tiroid nodülü ve tiroid kanseri riski mevcuttur. Bu nedenle akromegali hastaları tiroid nodülü yönünden aktif olarak izlenmeli, USG'de şüpheli bulgular saptanması durumunda ince iğne aspirasyon biyopsisi ile değerlendirilmelidir.

Anahtar kelimeler: Akromegali, tümör, tiroid kanseri.

Yılmaz N, Tazegül G, Sarı R, Altunbaş HA, Balcı MK. Akromegali hastalarında benign ve malign tümör sıklığı. Pam Tıp Derg 2020;13:415-423.

\begin{abstract}
Purpose: The aim of this study was to determine the prevalence of benign and malignant tumors in acromegaly patients in a single center.

Materials and methods: Records of 92 patients with acromegaly were retrospectively reviewed. Main clinical characteristics of the patients and characteristics and frequency of benign and malignant tumors were evaluated. Results: Median age of patients was $51(26-83)$ years, $52(56.5 \%)$ were female and $40(43.5 \%)$ were male. $4.3 \%(n=4)$ of the patients had a malignancy. All malignancies were thyroid papillary carcinoma. $76.1 \%$ of the patients had at least one benign tumor. Of patients underwent specific imaging modalities, thyroid nodules was present in $76 \%(n=57)$ of patients who underwent thyroid ultrasography $(n=74)$, colon polyps was present in $21.4 \%(n=15)$ of patients who underwent colonoscopy $(n=70)$, gallbladder polyps were present in $5.5 \%(n=4)$ of patients who underwent abdominal ultrasonography $(n=72)$ and benign breast lesions were found in $11.5 \%$ $(n=6)$ of women who underwent breast imaging $(n=52)$.

Conclusion: There is an increased risk of thyroid nodules and thyroid cancer in patients with acromegaly. Therefore, acromegaly patients should be actively monitored for thyroid nodules, and if suspicious findings are detected on ultrasonography, they should be evaluated further.
\end{abstract}

Key words: Acromegaly, tumor, thyroid cancer.

Yılmaz N, Tazegül G, Sarı R, Altunbaş HA, Balcı MK. Malign and benign tumor frequency in patients with acromegaly. Pam Med J 2020;13:415-423.

Nusret Yılmaz, Dr. Öğr. Üye. Akdeniz Üniversitesi Tıp Fakültesi Endokrinoloji ve Metabolizma Hastalıkları Bilim Dalı, Antalya, Türkiye, e-posta: nusretyilmazdr@yahoo.com (orcid.org/0000-0002-7494-1562) (Sorumlu Yazar)

Gökhan Tazegül, Arş. Gör. Akdeniz Üniversitesi Tıp Fakültesi İç Hastalıkları Anabilim Dalı, Antalya, Türkiye, e-posta: drgtazegul@gmail.com (orcid.org/0000-0002-0737-9450)

Ramazan Sarı, Prof. Dr. Akdeniz Üniversitesi Tıp Fakültesi Endokrinoloji ve Metabolizma Hastalıkları Bilim Dalı, Antalya, Türkiye, e-posta: drsari@hotmail.com (orcid.org/0000-0002-6989-1492)

Hasan Ali Altunbaş, Prof. Dr. Akdeniz Üniversitesi Tıp Fakültesi Endokrinoloji ve Metabolizma Hastalıkları Bilim Dalı, Antalya, Türkiye, e-posta: haltunbas@akdeniz.edu.tr (orcid.org/0000-0002-9468-6888)

Mustafa Kemal Balcı, Prof. Dr. Akdeniz Üniversitesi Tıp Fakültesi Endokrinoloji ve Metabolizma Hastalıkları Bilim Dalı, Antalya, Türkiye, e-posta: mbalci@akdeniz.edu.tr (orcid.org/0000-0002-6494-3249) 


\section{Giriş}

Akromegali, artmış büyüme hormonu $(\mathrm{BH})$ ve Insulin like Growth Factor-1 (IGF-1) sekresyonu ile karakterize, çeşitli morbiditelere neden olabilen, nadir görülen kronik bir hastalıktır. Akromegali hastalarında temel olarak kardiyovasküler, respiratuvar ve metabolik komplikasyonlara bağlı artmış bir morbidite ve mortalite riski söz konusudur [1]. Bunun yanında, tartışmalı olmakla beraber, akromegali hastalarında malign tümör sıklığında artış olduğu da bildirilmektedir. Genel olarak akromegali hastalarının malignite gelişimi için artmış bir riske sahip olduklarını bildiren çalışmalar yanında malignite riskinde bir artış olmadığını bildiren çalışmalar da mevcuttur [17]. Akromegali hastalarında tiroid bezi, kolon, safra kesesi gibi organlarda benign tümör sıklığının arttığı bildirilmiştir [5-6].

Akromegali hastalarında kanser insidansı üzerine olan ilgi temel olarak $\mathrm{BH}$ düzeyleri ile tümör gelişimi arasındaki ilişkiden kaynaklanmaktadır. Her ne kadar invitro ve invivo çalışmalar BH-IGF-1 aksı ile tümör oluşumu arasında güçlü bir ilişki olduğunu göstermiş olsa da akromegali hastalarında gerçek malignite insidansı kesin olarak bilinmemektedir [8-10]. $\mathrm{Bu}$ çalışmada merkezimizde izlenmekte olan akromegali hastalarındaki benign ve malign tümör sıklığının ve bunları etkileyen faktörlerin değerlendirilmesi amaçlanmıştır.

\section{Gereç ve yöntem}

Çalışmaya Endokrinoloji ve Metabolizma Hastalıkları Polikliniği'nde izlenmekte olan erişkin akromegali hastaları alındı. Çalışma için hastane başhekimliğinden veri kullanım izni alındı. Çalışma için Akdeniz Üniversitesi Tıp Fakültesi Klinik Araştırmalar Etik Kurulu'ndan onam alındı. Hastaların tıbbi kayıtları retrospektif olarak değerlendirilerek temel klinik karakteristikleri kaydedildi. Hastaların anamnez, fizik muayene, endoskopik değerlendirme, radyolojik görüntüleme bulguları ve patoloji raporları retrospektif olarak değerlendirildi. Hastalarda saptanmış olan malign ve benign tümörler kaydedilerek benign ve malign tümör sıklıkları ve bunların özellikleri incelendi.

Akromegalinin biyokimyasal tanısı, yüksek IGF-1 düzeyleri ve oral glukoz yükleme testi sonrası suprese olmayan $\mathrm{BH}$ düzeyleri varlığında konulmuştu [11, 12]. Akromegali için daha önce uygulanmış olan tedaviler kaydedildi (cerrahi girişimler ve radyoterapiler). Akromegaliye yönelik olarak halen almakta oldukları medikal tedaviler (somatostatin analogları (SA), kabergolin ve $\mathrm{BH}$ reseptör antagonisti ) incelendi. Hastaların akromegali yönünden hastalık aktiviteleri değerlendirildi. En son bakılan $\mathrm{BH}$ ve IGF-1 düzeylerine göre hastalar kür olmuş hastalar, hastalıkları kontrol altında olan hastalar ve aktif hastalar olmak üzere üç gruba ayrıldı. En son BH ve IGF-1 düzeyleri normal olan ve akromegaliye yönelik herhangi bir medikasyon almayan hastalar kür olmuş olarak kabul edildi. Medikal tedavi altında en son ölçülen random $\mathrm{BH}$ düzeyi 1 ng/ml'nin altında olan ve IGF-1 düzeyi yaşa göre belirlenen normal aralıkta olan hastaların akromegalisi kontrol altında olarak kabul edildi. Son IGF-1 düzeyleri yaşa göre belirlenen normal aralıkta olmakla beraber random $\mathrm{BH}$ düzeyi $1 \mathrm{ng} / \mathrm{ml}$ 'nin üzerinde olan hastalar ile son IGF-1 düzeyleri yaşa göre belirlenen normal aralıktan daha yüksek olan hastalar ise akromegali yönünden aktif hastalığa sahip olarak değerlendirildi [11, 13]. Serum IGF1 ve $\mathrm{BH}$ düzeyleri, Siemens Immulite 2000 Immunoassay analizörü kullanılarak (Siemens Healthcare Diagnostics, Forchheim, Germany), kemilüminesans immünassay yöntemi ile ölçüldü. IGF-1 kitine ait intra-assay CV: \%3,1, inter-assay CV: \%3,9 (kontrol değeri: $200 \mathrm{ng} /$ $\mathrm{mL}$ ) idi. Linearite sınırları: $15-1000 \mathrm{ng} / \mathrm{mL}$ idi. $\mathrm{BH}$ hormonu kitine ait intra-assay CV: \%3,4, inter-assay CV: \%5,5 (kontrol değeri: $5,3 \mathrm{ng} /$ $\mathrm{mL}$ ) idi. Kitin analitik sensitivitesi: $0,01 \mathrm{ng} / \mathrm{mL}$, linearite sınırları: 0,05-40 ng/mL idi.

\section{İstatistiksel yöntem}

Verilerin analizinde SPSS Windows versiyon 23.0 kullanıldı. Tanımlayıcı verilerde sürekli değişkenlerin gösterilmesinde medyan (minimum-maksimum), kategorik değişkenlerin gösterilmesinde ise sayısal değerleri ve yüzdeler kullanıldı. İstatistiksel analizde kategorik verilerin arasındaki ilişkinin değerlendirmesinde ki-kare testi, sürekli değişkenlerin gruplar arası dağılımlarının değerlendirmede MannWhitney-U testi kullanıldı. Tüm istatistiki testler için $p<0,05$ istatistiksel anlamlılık sınırı kabul edildi.

\section{Bulgular}

Çalışmaya alınan hastaların 52'si $(\% 56,5)$ kadın, 40 ' $(\% 43,5)$ erkek ve medyan yaşları 
51 (26-83) yıl idi. Akromegali için medyan hastalık süresi 10 (1-35) yıldı. Hastaların temel karakteristikleri ve sahip oldukları diğer komorbiditeler Tablo 1'de verilmiştir. Akromegali hastalarının 3'ünde $(\% 3,3)$ klinik olarak konulmuş multiple endokrin neoplazi Tip 1 tanısı vardı. Hastaların 29'unda (\%31,5) kolelithiazis ve 21 'inde $(\% 22,8)$ kolesistektomi öyküsü mevcuttu. Hastaların 15'inde $(\% 16,3)$ tiroidektomi öyküsü vardı. Tiroidektomi yapılan hastaların 4'ünün (tüm hastaların \%4,3'ünün) patoloji sonucu papiller karsinom olarak raporlanmıştı. Akromegali hastalarının tiroid fonksiyonları değerlendirildiğinde hastaların $\% 66,3$ 'ünde $(n=61)$ normal tiroid fonksiyonları, $\% 7,6$ 'sında $(n=7)$ primer hipotiroidi, \%3,3'ünde $(n=3)$ subklinik hipertiroidi, \%1,1'inde $(n=1)$ hipertiroidi ve \%21,7'sinde $(n=20)$ sekonder hipotiroidi mevcuttu. Hastaların \%30,4'ünde $(n=28)$ hipofizer düzeyde en az bir hormonal yetmezlik vardı. Hastaların \%18,5'inde $(n=17)$ adrenal yetmezlik, \%21,7'sinde $(n=20)$ santral hipotiroidi ve \%25'inde $(n=23)$ hipogonadizm mevcuttu.

Hastalarda saptanan benign ve malign tümörler ve bunların sıklığı Tablo 2'de verilmiştir. Hastaların \%4,3'ünde ( $n=4)$ malignite mevcuttu. Hastalarda saptanan malignitelerin tümü tiroid malignitesiydi ve hepsinin histopatolojik alt tipi papiller karsinomdu. Hastalarda tiroid malignitesi dışında herhangi bir malignite mevcut değildi. Nodüler veya multinodüler guatrı olan toplam 57 hastanın 29'una $(\% 50,9)$

Tablo 1. Hastaların temel karakteristikleri $(n=92)$.

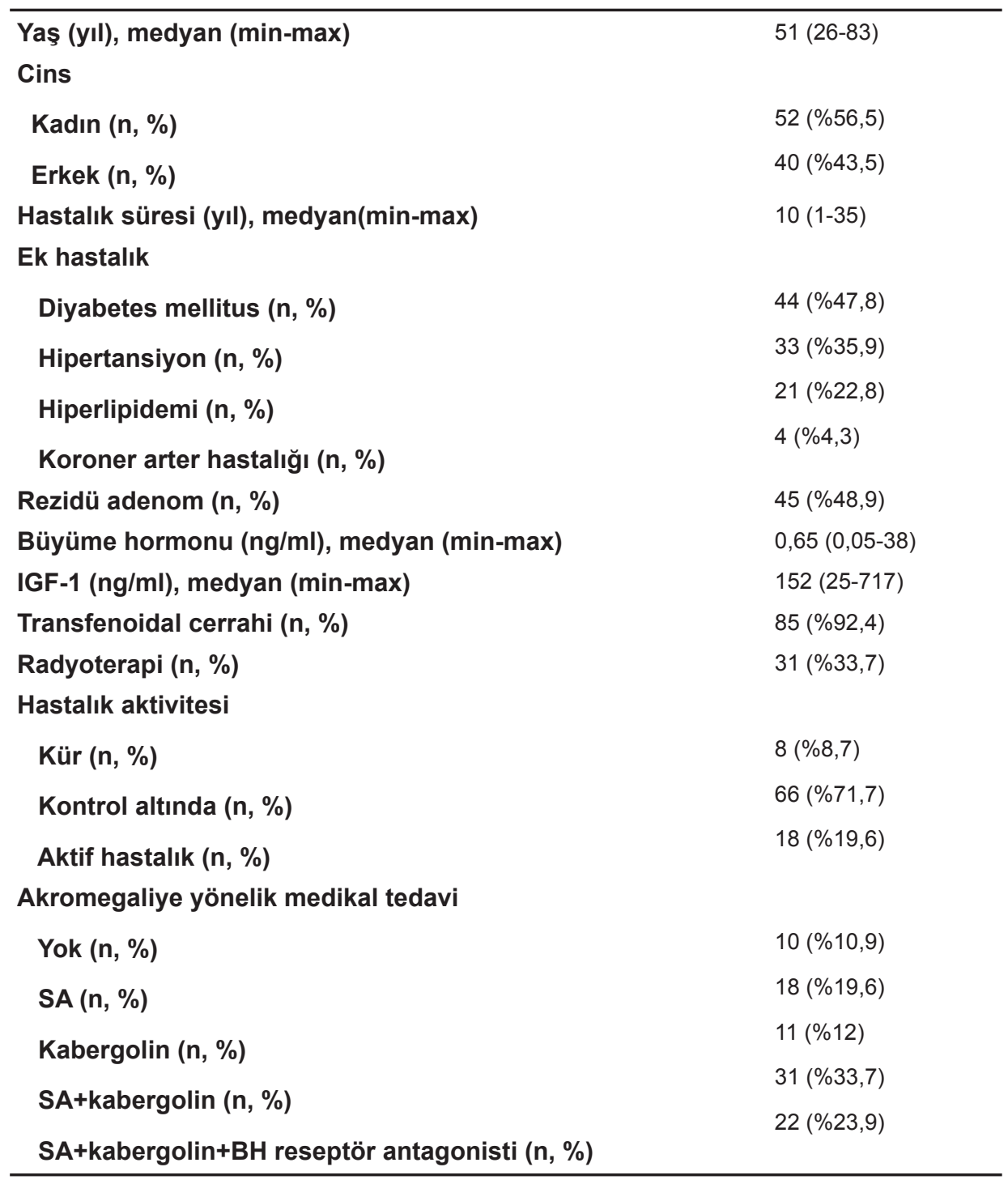

IGF-1: Insülin-like Growth Faktör-1, SA: Somatostatin analoğu, BH: Büyüme hormonu 
Tablo 2. Hastalarda saptanan benign ve malign tümörler.

\begin{tabular}{ll}
\hline Malignite (n, \%) & $4(\% 4,3)$ \\
$\quad$ Tiroid malignitesi & $4(\% 4,3)$ \\
Kolonoskopi yapılan hasta sayısı (n) & 70 \\
Kolon polibi (n, \%) & $15(\% 21,4)$ \\
Abdominal USG yapılan hasta sayısı (n) & 72 \\
$\quad$ Safra kesesi polibi (n, \%) & $4(\% 5,5)$ \\
Tiroid USG yapılan hasta sayısı (n) & 74 \\
$\quad$ Normal (n, \%) & $17(\% 23)$ \\
$\quad$ Nodüler Guatr (n, \%) & $10(\% 13,5)$ \\
Multinodüler guatr (n, \%) & $47(\% 63,5)$ \\
Meme USG/mammografi yapılan hasta sayısı (n) & 52 \\
Benign meme lezyonu (n, \%) & $6(\% 11,5)$ \\
Pelvik USG yapılan hasta sayısı (n) & 52 \\
Uterin miyom & $4(\% 7,7)$ \\
Endometriyal polip & $1(\% 1,9)$ \\
Paratiroid adenomu & $3(\% 3,2)$ \\
\hline
\end{tabular}

USG: Ultrasonografi

tiroid ince iğne aspirasyon biyopsisi yapılmıştı. Tiroid ince iğne aspirasyon biyopsisi sonuçları, Bethesda sınıflamasına göre, hastaların 24 'ünde $(\% 82,8)$ benign, ikisinde $(\% 6,9)$ malign, birinde $(\% 3,4)$ malignite şüpheli, birinde $(\% 3,4)$ önemi belirsiz atipi (iki kez) ve birinde $(\% 3,4)$ nondiagnostik (üç kez) olarak raporlanmıştı. Hastaların \%76,1'inde $(n=70)$ en az bir benign tümör mevcuttu. Hastaların \%57,6'sında ( $n=53$ ) bir, \%15,2'sinde (n=14) iki, \%2,2'sinde (n=2) üç ve $\% 1,1$ 'inde dört benign tümör bulunmaktaydı.

Malignitesi olan hastalar çıkarıldıktan sonra geriye kalan 88 hastanın benign bir tümöre sahip olup olmamalarına göre iki gruba ayrılarak verileri karşılaştırıldı. Bu iki grubun karşılaştırma verileri Tablo 3'de verilmiştir. Benign tümörü olan grupta kadın oranı erkeklerden daha fazlaydı (sırası ile \%63,6 ve \%36,4, $p=0,02$ ). Benign tümörü olan grupta diabetes mellitus ve hipertansiyon sıklığı benign tümörü olmayan gruba oranla daha sıktı ( $p$ değeri sırası ile 0,023 ve 0,012 ) (Tablo 3 ). Benign tümörü olan ve olmayan hastalar arasında GH, IGF-1, hastalık süresi ve hastalık aktivitesi açısından bir fark saptanmadı.

\section{Tartışma}

Çalışmamızda akromegali hastalarındaki malignite sıklığı \%4,3 olarak saptanmıştır. Saptanan malignitelerin tümü tiroid kanseri idi ve hepsinin histopatolojik alt tipi papiller karsinomdu. Çalışmamızdaki akromegali hastalarında tiroid kanseri dışında herhangi bir malignite saptanmamıştır.

Akromegali hastalarındaki malignite gelişme riski ve malignite insidansı tam olarak bilinmemektedir. Akromegali hastalarında malignite riskinin artıp artmadığı konusunda farklı sonuçlar mevcuttur. Bunun temel nedeni akromegalinin nadir bir hastalık olması nedeni ile çalışmaların çoğunun retrospektif ve tek merkezden yapılan çalışmalar şeklinde olmasıdır. Yapılan çalışmaların çoğunda akromegali hastalarında kanser insidansının normal popülasyona göre daha yüksek olduğu bildirilmiştir [14-16]. Wolinski ve ark. [4] akromegali hastalarında herhangi bir tipte malignite gelişme riskinin, kontrol grubuna göre, üç kattan fazla arttığını bildirmişlerdir. Dal ve ark. [17] yaptıkları ve standardize insidans oranlarının (Standardized Incidance Ratio=SIR) değerlendirildiği meta-analizde, akromegali hastalarında toplam kanser insidansının arttığını göstermişlerdir. Buna karşılık akromegali hastalarındaki kanser insidansının normal popülasyonla aynı olduğunu bildiren çalışmalar da mevcuttur [1]. Avrupa'dan birçok merkezden 3173 akromegali hastasının verilerini içeren uluslararası veri tabanının değerlendirildiği çalışmada total kanser sıklığında ve spesifik kanser tiplerinin sıklığında bir artış saptanmamıştır [7]. Malignite sıklığının artıp artmadığı konusundaki bu kafa karıştırıcı sonuçlar, temel olarak akromegalinin nadir bir 
Tablo 3. Benign tümörü olan ve olmayan hastaların sonuçları.

\begin{tabular}{|c|c|c|c|}
\hline & $\begin{array}{l}\text { Benign tümör } \\
\text { olmayan hastalar } \\
(n=22)\end{array}$ & $\begin{array}{l}\text { Benign tümörü olan } \\
\text { hastalar }(n=66)\end{array}$ & $p$ değeri \\
\hline Yaş (yıl), medyan (min-max) & $48(26-83)$ & $52(36-76)$ & 0,36 \\
\hline \multicolumn{4}{|l|}{ Cins } \\
\hline Kadın (n, \%) & $8(\% 36,4)$ & $42(\% 63,6)$ & 0,02 \\
\hline Erkek (n, \%) & $14(\% 63,6)$ & $24(\% 36,4)$ & \\
\hline \multicolumn{4}{|l|}{ Ek hastalık } \\
\hline Diabetes mellitus (n, \%) & $6(\% 27,3)$ & $36(\% 54,5)$ & 0,023 \\
\hline Hipertansiyon (n, \%) & $3(\% 13,6)$ & $28(\% 42,4)$ & 0,012 \\
\hline Hiperlipidemi (n, \%) & $3(\% 13,6)$ & $18(\% 27,3)$ & 0,156 \\
\hline Koroner arter hastalığı (n, \%) & $0(\% 0)$ & $4(\% 6,1)$ & 0,309 \\
\hline Hastalık süresi (yıl), medyan(min-max) & $10(2-25)$ & $11(1-35)$ & 0,91 \\
\hline Büyüme hormonu (ng/ml), medyan(min-max) & $0,65(0,05-10,5)$ & $0,72(0,1-38)$ & 0,44 \\
\hline IGF-1 (ng/ml), medyan (min-max) & $156(25-717)$ & $172(44-485)$ & 0,84 \\
\hline \multicolumn{4}{|l|}{ Hastalık aktivitesi } \\
\hline Kür (n, \%) & $1(\% 4,5)$ & $7(\% 10,6)$ & 0,35 \\
\hline Kontrol altında (n, \%) & $15(\% 68,2)$ & $48(\% 72,7)$ & 0,43 \\
\hline Aktif hastalık (n, \%) & $6(\% 27,3)$ & $11(\% 16,7)$ & 0,27 \\
\hline Transfenoidal cerrahi (n, \%) & $19(\% 86,4)$ & $62(\% 93,9)$ & 0,23 \\
\hline Radyoterapi (n, \%) & $7(\% 31,8)$ & $23(\% 34,8)$ & 0,506 \\
\hline Rezidü adenom (n, \%) & $7(\% 35)$ & $35(\% 53,8)$ & 0,11 \\
\hline
\end{tabular}

IGF-1: Insülin-like Growth Faktör-1

hastalık olması nedeni ile çalışmaların çoğunun küçük ölçekli olmasından kaynaklanmaktadır. Daha önce yapılan çalışmalarda akromegali hastalarında malignite prevalansı $\% 2$ ile $\% 21,3$ arasında değişen oranlarda raporlanmıştır $[4,7$, $18,19]$. On yedi çalışmanın verilerinin incelendiği bir değerlendirmede ortalama kanser prevalansı $\% 10,8 \quad(\% 4,8-21,3)$ olarak bildirilmiştir [20]. Türkiye'den yapılan çalışmalarda akromegali hastalarında malignite sıklığı \%15 ile \%21,3 arasında değişen oranlarda bildirilmiştir [18, 19]. Bizim çalışmamızda ise akromegali hastalarında malignite prevalansı \%4,3 idi ve bu sıklık daha önce Türkiye'de yapılmış olan çalışmalarda bildirilen oranlardan daha düşüktür.

Tiroid kanseri akromegalide en sık görülen maliginitelerden biridir [18]. Akromegali hastalarında en sık raporlanan tiroid kanseri tipi, bizim çalışmamızda da olduğu gibi, diferansiye tiroid kanseridir [2, 18, 19, 21]. Hasta kayıtları baz alınarak yapılan çalışmalarda tiroid kanseri riskinin arttığını bildiren çalışmalar yanında artmadığını bildiren çalışmalar da mevcuttur [1, $3,14,22-25]$. Son zamanlarda yapılan bir metaanalizde tiroid kanseri riskinin arttığı bildirilmiştir (SIR=9,2 (\%95 Cl, 4,2-19,9)) [17]. Akromegali hastalarında tiroid kanseri sıklığı \%0,34 ile 10,6 arasında raporlanmıştır $[2,4,7,18,19,21,26$, 27]. Türkiye'den yapılan çalışmalarda ise tiroid kanseri prevalansı \%4,7 ile 11 arasında değişen oranlarda bildirilmiştir $[18,19,28]$. Wolinski ve ark. [5] yaptıkları bir meta-analizde akromegali hastalarında tiroid kanseri prevalansını \%4,3 olarak hesaplamışlardır. Bizim çalışmamızda da Wolinski ve ark.'nın yaptıkları meta-analizde bildirilenle aynı prevalans saptanmıştır. Normal popülasyon için papiller tiroid kanseri prevalansı $\% 0,3$ ile \%2,4 arasında değişen oranlarda bildirilmiştir [29-31]. Çalışmamızda saptanan tiroid kanseri sıklığı akromegali hastaları için önceden bildirilen oranlar ile benzer, normal popülasyon için bildirilen oranlardan ise daha yüksekti. Bu bulgumuz akromegali hastalarında 
tiroid kanseri riskinin arttığını, hastaların tiroid nodülü yönünden mutlaka taranması ve şüpheli bulgular mevcudiyetinde ince iğne aspirasyon biyopsisi ile değerlendirilmesi gerektiğini desteklemektedir.

Akromegali hastalarında meme ve diğer organ kanserlerinde bir risk artışı olduğu kesin olarak gösterilememiştir [11]. Bazı çalışmalarda bazı organ malignitelerinin sıklığının arttığı bildirilmiştir. Akromegali hastalarında meme ve kolon kanseri riskinin arttığını bildiren çalışmalar mevcuttur [1, 4, 14, 32]. Bazı çalışmalarda ise meme kanseri sıklığının artmadığı bildirilmiştir [1, 7, 14, 24, 33]. Daha önce yapılan çalışmalarda meme kanseri prevalansı \%0,5 ile $\% 5,4$ arasında değişen oranlarda bildirilmiştir [4, 7, 18, 19, 34]. Akromegali hastalarında, kolon polipi sıklığının arttığı net olarak gösterilmiş olmakla beraber, kolon kanseri sıklığının artıp artmadığı konusunda farklı sonuçlar mevcuttur [23]. Bazı otörler akromegali hastalarında kolon kanseri riskinin arttığını bildirirken bazıları ise riskin artmadığını bildirmişlerdir [6, 25, 35]. Akromegali hastalarında kolon kanseri sıklığını \%1,2 ile \%2 arasında değişen oranlarda bildiren çalışmalar mevcuttur [4, 36]. Bununla beraber kolon malignitesi saptanmadığını bildiren çalışmalar da mevcuttur [37]. Son zamanlarda yapılan meta-analiz, SIR değerlerine göre, akromegali hastalarında kolorektal, tiroid, meme, gastrik ve üriner sistem kanseri riskinde artış olduğu bildirilmiştir [17]. Akromegali hastalarında spesifik organ maligniteleri için oldukça değişken prevalans oranları bildirilmiştir [7]. Ancak bizim çalışmamızda tiroid kanseri dışında diğer organlardan kaynaklanan herhangi bir malignite saptanmamıştır.

Akromegali hastalarında benign tümöral oluşumlar sık olarak saptanmaktadır [2]. Akromegali hastalarının değerlendirildiği retrospektif bir çalışmada benign tümör sıklığı \%71,6 olarak bildirilmiştir [38]. Bizim çalışmamızda da hastaların \%76,1'inde en az bir benign tümör mevcuttu ve benign tümörü olan grupta kadın cinsiyet oranı, benign tümörü olmayan gruba oranla, istatistiksel olarak anlamlı düzeyde daha yüksekti. Bu durum, erkeklerden farklı olarak kadınlara rutin olarak yapılmış olan meme görüntülemelerinde saptanan meme lezyonlarından ve pelvik usg'de saptanan uterus lezyonlarından kaynaklanmış olabilir. Benign tümörü olan hastalarda, olmayanlara oranla, diyabet ve hipertansiyon sıklığı da daha fazlaydı. Bu bulgularımız, özellikle de diyabeti ve hipertansiyonu olan hastalar olmak üzere, akromegali hastalarının malign tümörler yanında benign tümörler yönünden de değerlendirilmeleri gerektiğini düşündürmektedir.

Akromegali hastalarında en sık saptanan benign tümör tiroid nodülüdür. Türkiye dışından yapılmış olan çalışmalarda akromegali hastalarında tiroid nodülü sıklığı \%34 ile \%69,8 arasında değişen oranlarda bildirilmiştir [2, 7 , 39, 40]. Türkiye'den yapılan çalışmalarda ise akromegali hastalarında tiroid nodülü prevalansı $\% 62$ ile \%72,1 arasında raporlanmıştır [18, $19,28]$. Bizim çalışmamızda akromegali hastalarında tiroid nodülü sıklığı \%77 saptanmış olup bu değer daha önce raporlanan prevalans oranlarından daha yüksektir.

Akromegali hastalarında kolon polipi sıklığının arttığı gösterilmiştir [6]. Akromegali hastalarında kolon polipi sıklığının \%13 ile \%38 arasında olduğu bildirilmiştir [7, 37, 41-44]. Türkiye'den yapılan çalışmalarda akromegali hastalarındaki kolon polipi sıklığı \%30,2 ile \%40 arasında bildirilmiştir [37, 42, 45, 46]. Bizim çalışmamızda saptadığımız sıklık genel literatürde bildirilen prevalansa benzer, ancak Türkiye'den yapılmış olan çalışmalarda bildirilen prevalanstan daha düşüktür.

Akromegali hastalarında safra kesesi polipi prevalansının arttığı bildirilmiştir. Annamalai ve ark. [47] yaptıkları çalışmada akromegali hastalarında safra kesesi polipi prevalansının $\% 29,03$ olduğunu ve kontrol hastalarına göre safra kesesi polipi gelişme riskinin daha yüksek olduğunu bildirmişlerdir. Kurimoto ve ark. [2] da akromegali hastalarında \%14,3 gibi yüksek bir safra kesesi polipi prevalansı bildirmişlerdir. Başka bir çalışmada ise safra kesesi polipi prevalansı \%4,47 gibi daha düşük bir oranda bildirilmiştir [38]. Bizim çalışmamızda da safra kesesi polipi prevalansı \%5,5 olarak saptanmış olup, bu oran Annamalai ve ark. [47] yaptıkları çalışmada kontrol grubunda saptanan prevalansa $(\% 4,62)$ yakındır.

Çalışmamızın kısıtlayıcı yönü az sayıda hastayı içeren retrospektif bir tek merkez çalışması olmasıdır. Tümör değerlendirilmesi için hastalara önerilen rutin tarama tetkiklerinin bazı hastalar tarafından kabul edilmemesine bağlı tümör değerlendirme oranı düşüklüğü 
ve buna bağlı ortaya çıkan veri azlığı da çalışmamızın kısıtlayıcı yönlerinden biridir. Diğer bir kısıtlayıcı yönü de kontrol grubunun olmamasıdır.

Sonuç olarak, akromegali hastalarında artmış tiroid nodülü ve tiroid kanseri riski nedeni ile hastalar tiroid nodülü yönünden dinamik olarak izlenmeli ve saptanan nodüller, şüpheli ultrasonografik bulgular varlığında, ince iğne aspirasyon biyopsisi ile değerlendirilmelidir. Akromegali hastalarında gerçek malignite riskinin ve gerçek malignite insidansının belirlenebilmesi için çok merkezli ve kontrollü çalışmalar yapılması gereklidir.

Çıkar ilişkisi: Yazarlar çıkar ilişkisi olmadığını beyan eder.

\section{Kaynaklar}

1. Orme SM, McNally RJ, Cartwright RA, Belchetz PE. Mortality and cancer incidence in acromegaly: a retrospective cohort study. United Kingdom Acromegaly Study Group. J Clin Endocrinol Metab 1998;83:27302734. https://doi.org/10.1210/jcem.83.8.5007

2. Kurimoto M, Fukuda I, Hizuka N, Takano K. The prevalence of benign and malignant tumors in patients with acromegaly at a single institute. Endocr J 2008;55:67-71. https://doi.org/10.1507/endocrj.k07e010

3. Terzolo M, Reimondo G, Berchialla P, et al. Acromegaly is associated with increased cancer risk: a survey in Italy. Endocr Relat Cancer 2017;24:495-504. https:// doi.org/10.1530/ERC-16-0553

4. Wolinski K, Stangierski A, Dyrda K, et al. Risk of malignant neoplasms in acromegaly: a case-control study. J Endocrinol Invest 2017;40:319-322. https:// doi.org/10.1007/s40618-016-0565-y

5. Wolinski K, Czarnywojtek A, Ruchala M. Risk of thyroid nodular disease and thyroid cancer in patients with acromegaly--meta-analysis and systematic review. PLoS One 2014;9:e88787. https://doi.org/10.1371/ journal.pone. 0088787

6. Rokkas T, Pistiolas D, Sechopoulos P, Margantinis G, Koukoulis G. Risk of colorectal neoplasm in patients with acromegaly: a meta-analysis. World J Gastroenterol 2008;14:3484-3489. https://doi. org/10.3748/wjg.14.3484

7. Petrossians P, Daly AF, Natchev E, et al. Acromegaly at diagnosis in 3173 patients from the Liege Acromegaly Survey (LAS) Database. Endocr Relat Cancer 2017;24:505-518. https://doi.org/10.1530/ERC-170253

8. Chopin LK, Veveris-Lowe TL, Philipps AF, Herington
AC. Co-expression of $\mathrm{GH}$ and $\mathrm{GHR}$ isoforms in prostate cancer cell lines. Growth Horm IGF Res 2002;12:126136. https://doi.org/10.1054/ghir.2002.0271

9. Slater $M$, Cooper $M$, Murphy $C R$. Human growth hormone and interleukin-6 are upregulated in endometriosis and endometrioid adenocarcinoma. Acta Histochem 2006;108:13-18. https://doi.org/10.1016/j. acthis.2006.01.004

10. Giovannucci E, Pollak MN, Platz EA, et al. A prospective study of plasma insulin-like growth factor- 1 and binding protein-3 and risk of colorectal neoplasia in women. Cancer Epidemiol Biomarkers Prev 2000;9:345-349.

11. Katznelson L, Laws ER Jr, Melmed S, et al. Acromegaly: an endocrine society clinical practice guideline. J Clin Endocrinol Metab 2014;99:3933-3951. https://doi. org/10.1210/jc.2014-2700

12. Katznelson L, Atkinson JL, Cook DM, Ezzat SZ, Hamrahian AH, Miller KK. American association of clinical endocrinologists medical guidelines for clinical practice for the diagnosis and treatment of acromegaly--2011 update. Endocr Pract 2011;17:1-44. https://doi.org/10.4158/ep.17.s4.1

13. Giustina A, Chanson P, Bronstein MD, et al. A consensus on criteria for cure of acromegaly. J Clin Endocrinol Metab 2010;95:3141-3148. https://doi. org/10.1210/jc.2009-2670

14. Baris D, Gridley G, Ron E, et al. Acromegaly and cancer risk: a cohort study in Sweden and Denmark. Cancer Causes Control 2002;13:395-400. https://doi. org/10.1023/a:1015713732717

15. Higuchi $Y$, Saeki $N$, Luchi $T$, et al. Incidence of malignant tumors in patients with acromegaly. Endoc J 2000;47:57-60. https://doi.org/10.1507/endocrj.47. supplmarch_s57

16. Popovic V, Damjanovic S, Micic D, et al. Increased incidence of neoplasia in patients with pituitary adenomas. The Pituitary Study Group. Clin Endocrinol (Oxf) 1998;49:441-445. https://doi.org/10.1046/j.13652265.1998.00536.x

17. Dal J, Leisner MZ, Hermansen $\mathrm{K}$, et al. Cancer incidence in patients with acromegaly: A cohort study and meta-analysis of the literature. J Clin Endocrinol Metab 2018;103:2182-2188. https://doi.org/10.1210/ jc. 2017-02457

18. Gullu BE, Celik O, Gazioglu N, Kadioglu P. Thyroid cancer is the most common cancer associated with acromegaly. Pituitary 2010;13:242-248. https://doi. org/10.1007/s11102-010-0224-9

19. Dagdelen S, Cinar N, Erbas T. Increased thyroid cancer risk in acromegaly. Pituitary 2014;17:299-306. https:// doi.org/10.1007/s11102-013-0501-5

20. Boguszewski CL, Ayuk J. Management of endocrine 
disease: acromegaly and cancer: an old debate revisited. Eur J Endocrinol 2016;175:147-156. https:// doi.org/10.1530/EJE-16-0178

21. Gasperi M, Martino E, Manetti L, et al. Prevalence of thyroid diseases in patients with acromegaly: results of an Italian multi-center study. J Endocrinol Invest 2002;25:240-245. https://doi.org/10.1007/BF03343997

22. Ron E, Gridley G, Hrubec Z, Page W, Arora S, Fraumeni JF Jr. Acromegaly and gastrointestinal cancer. Cancer 1991;68:1673-1677. https://doi. org/10.1002/1097-0142(19911015)68:8<1673::aidcncr2820680802>3.0.co;2-0

23. Colao A, Ferone D, Marzullo P, Lombardi G. Systemic complications of acromegaly: epidemiology, pathogenesis and management. Endocr Rev 2004;25:102-152. https://doi.org/10.1210/er.20020022

24. Kauppinen-Makelin $\mathrm{R}$, Sane $\mathrm{T}$, Valimaki MJ, et al. Increased cancer incidence in acromegaly-a nationwide survey. Clin Endocrinol (Oxf) 2010;72:278279. https://doi.org/10.1111/j.1365-2265.2009.03619.x

25. Petroff D, Tonjes A, Grussendorf M, et al. The Incidence of cancer among acromegaly patients: results from the German Acromegaly Registry. J Clin Endocrinol Metab 2015;100:3894-3902. https://doi.org/10.1210/jc.20152372

26. Tita P, Ambrosio MR, Scollo C, et al. High prevalence of differentiated thyroid carcinoma in acromegaly. Clin Endocrinol (Oxf) 2005;63:161-167. https://doi. org/10.1111/j.1365-2265.2005.02316.x

27. dos Santos MC, Nascimento GC, Nascimento AG, et al. Thyroid cancer in patients with acromegaly: a casecontrol study. Pituitary 2013;16:109-114. https://doi. org/10.1007/s11102-012-0383-y

28. Dogansen SC, Salmaslioglu A, Yalin GY, Tanrikulu $S$, Yarman S. Evaluation of the natural course of thyroid nodules in patients with acromegaly. Pituitary 2019;22:29-36. https://doi.org/10.1007/s11102-0180923-1

29. Kim SY, Han KH, Moon HJ, Kwak JY, Chung WY, Kim EK. Thyroid nodules with benign findings at cytologic examination: results of long-term follow-up with US. Radiology 2014;271:272-281. https://doi.org/10.1148/ radiol.13131334

30. Durante C, Costante G, Lucisano G, et al. The natural history of benign thyroid nodules. JAMA 2015;313:926935. https://doi.org/10.1001/jama.2015.0956

31. Rosario PW, Calsolari MR. What is the best criterion for repetition of fine-needle aspiration in thyroid nodules with initially benign cytology? Thyroid 2015;25:11151120. https://doi.org/10.1089/thy.2015.0253

32. Nabarro JDN. Acromegaly. Clin Endocrinol (Oxf) 1987;26:481-512. https://doi. org/10.1111/j.1365-2265.1987.tb00805.x

33. Dal J, Feldt-Rasmussen $U$, Andersen $M$, et al.
Acromegaly incidence, prevalence, complications and long-term prognosis: a nationwide cohort study. Eur J Endocrinol 2016;175:181-190. https://doi.org/10.1530/ EJE-16-0117

34. Mestron A, Webb SM, Astorga R, et al. Epidemiology, clinical characteristics, outcome, morbidity and mortality in acromegaly based on the Spanish Acromegaly Registry (Registro Espanol de Acromegalia, REA). Eur J Endocrinol 2004;151:439-446. https://doi. org/10.1530/eje.0.1510439

35. Wassenaar MJ, Cazemier M, Biermasz NR, et al. Acromegaly is associated with an increased prevalence of colonic diverticula: a case-control study. J Clin Endocrinol Metab 2010;95:2073-2079. https:// doi.org/10.1210/jc.2009-1714

36. Jenkins PJ, Besser M. Clinical perspective: acromegaly and cancer: a problem. J Clin Endocrinol Metab 2001;86:2935-2941. https://doi.org/10.1210/ jcem.86.7.7634

37. Iliaz R, Dogansen SC, Tanrikulu S, et al. Predictors of colonic pathologies in active acromegaly: single tertiary center experience. Wien Klin Wochenschr 2018;130:511-516. https://doi.org/10.1007/s00508018-1367-3

38. Matyjaszek-Matuszek B, Obel E, Lewicki M, Kowalczyk-Boltuc J, Smolen A. Prevalence of neoplasms in patients with acromegaly-the need for a national registry. Ann Agric Environ Med 2018;25:559561. https://doi.org/10.26444/aaem/85652

39. Manavela M, Vigovich C, Danilowicz K, et al. Thyroid autoimmune disorders in patients with acromegaly. Pituitary 2015;18:912-915. https://doi.org/10.1007/ s11102-015-0670-5

40. Baldys-Waligorska A, Krzentowska A, Golkowski F, Sokolowski G, Hubalewska-Dydejczyk A. The prevalence of benign and malignant neoplasms in acromegalic patients. Endokrynol Pol 2010;61:29-34.

41. Delhougne B, Deneux $C, A b s$, et al. The prevalence of colonic polyps in acromegaly: a colonoscopic and pathological study in 103 patients. J Clin Endocrinol Metab 1995;80:3223-3226. https://doi.org/10.1210/ jcem.80.11.7593429

42. Koksal AR, Ergun M, Boga S, etal. Increased prevalence of colorectal polyp in acromegaly patients: a casecontrol study. Diagn Ther Endosc 2014;2014:152049. https://doi.org/10.1155/2014/152049

43. Gonzalez B, Vargas G, Mendoza V, Nava M, Rojas $\mathrm{M}$, Mercado M. The prevalence of colonic polyps in patients with acromegaly: a case-control, nested in a cohort colonoscopic study. Endocr Pract 2017;23:594549. https://doi.org/10.4158/EP161724.OR

44. Bogazzi F, Cosci C, Sardella C, et al. Identification of acromegalic patients at risk of developing colonic adenomas. J Clin Endocrinol Metab 2006;91:13511356. https://doi.org/10.1210/jc.2005-2500

45. Berker D, Ates Tutuncu, Y, Isik, S, et al. Prevalence 
and recurrence rate of colonic lesions in acromegalic patients. Cent Eur J Med 2010;5:704-711. https://doi. org/10.2478/s11536-010-0041-6

46. Kurtulmus N, Yarman, S, Demir, K. Association between skin tags and colonic polyps in patients with acromegaly. Turkish Journal of Endocrinology and Metabolism 2005;9:45-47.

47. Annamalai AK, Gayton EL, Webb A, et al. Increased prevalence of gallbladder polyps in acromegaly. J Clin Endocrinol Metab 2011;96:1120-1125. https://doi. org/10.1210/jc.2010-2669

Etik onayı: Çalışma için Akdeniz Üniversitesi Klinik Araştırmalar Etik Kurulu'ndan 05.02.2020 tarih ve KAEK-97 numaralı kararı ile onay alınmıştır. 